\title{
EMBRYO DEATHS IN REPRODUCTION AND EMBRYO RESEARCH: A REPLY TO MURPHY'S DOUBLE EFFECT ARGUMENT
}

\section{Katrien Devolder}

\section{ABSTRACT}

The majority of embryos created in natural reproduction die spontaneously within a few weeks of conception. Some have argued that, therefore, if one believes the embryo is a person (in the normative sense) one should find 'natural' reproduction morally problematic. An extension of this argument holds that, if one accepts embryo deaths in natural reproduction, consistency requires that one also accepts embryo deaths that occur in (i) assisted reproduction via (in vitro fertilisation) IVF and (ii) embryo research. In a recent paper in this journal, Timothy Murphy criticizes both the initial argument and its extension. Murphy argues that double-effect reasoning can justify embryo deaths both in natural reproduction and IVF, but not in embryo research. Thus, according to Murphy, one can, without being inconsistent, (1) believe the embryo is a person and accept natural reproduction and IVF, and (2) accept natural reproduction and IVF, while rejecting embryo research on the ground that it involves embryo deaths. I show that Murphy's argument is problematic because double effect cannot justify embryo deaths in standard IVF practices. The problem is that the proportionality criterion of double effect is not met by such practices. Thus, Murphy's argument fails to support (1) and (2). An implication of his argument failing to support (2) is that it does not defeat the position I have defended in the past - that if one accepts standard IVF practices one should also accept embryo research, including research with embryos created solely for that purpose. 
The majority of embryos created in natural reproduction die spontaneously within a few weeks of conception, with the riskiest time being that before implantation into the uterine wall.[1,2,3] According to some estimates, a mother of three children could be expected to have also had approximately five spontaneous abortions.[4] Some have argued that, therefore, if one believes the embryo is a person (in the normative sense), one should find 'natural' reproduction morally problematic and perhaps even reject it.[5,6] An extension of this argument holds that, if one accepts embryo deaths in natural reproduction, consistency requires that one also accepts embryo deaths that occur in (i) assisted reproduction via IVF and (ii) embryo research.[7]

In a recent paper in this journal, Timothy Murphy criticizes both arguments.[8] Murphy argues that double-effect reasoning can justify embryo deaths both in natural reproduction and IVF, but not in embryo research. Thus, according to Murphy, one can, without being inconsistent, (1) believe the embryo is a person and accept natural reproduction and IVF, and (2) accept natural reproduction and IVF, while rejecting embryo research on the ground that it involves embryo deaths. I am myself sceptical of the normative force of the doctrine of double effect (henceforth just 'double effect'), but for the sake of argument I assume here that it is a valid principle. I agree with Murphy that an appeal to double effect could then perhaps justify embryo deaths in natural reproduction, even if the embryo is a person, but I disagree with his claim that it can justify embryo deaths in standard IVF practices. The problem is that the proportionality criterion of double effect is not met by such practices. Thus, Murphy's argument fails to support (1) and (2). An implication of his argument failing to support (2) is that it does not defeat the position I have defended in the past - that if one accepts standard IVF practices one should also accept embryo research, including with embryos created solely for that purpose (there may, of course, be other reasons for why this position is incorrect). 
In what follows, I provide reasons for why I think my views on this matter are correct. Just like Murphy does in his paper, I assume for the sake of argument that an embryo, from the moment of conception, has the same moral status as you and me or, in Murphy's words, that the embryo is a 'metaphysical person'. This view is firmly held by many who oppose IVF and/or embryo research.

\section{NATURAL REPRODUCTION}

Let us start with Murphy's rebuttal of the argument that if one believes the early embryo is a person then one should find natural reproduction morally problematic. According to Murphy, this argument fails because embryo deaths in natural reproduction (which he refers to as 'conception in vivo') can be justified by double effect.

There are various formulations of double effect, but basically the principle holds that it may be permissible to bring about a harm as a foreseen but unintended side effect of an action that is aimed at some good end, even though it is impermissible to bring about the same harm as a means to achieving that end.

Murphy claims to model his analysis on Aquinas' formulation of double effect. Aquinas is credited with introducing the principle in his discussion of the permissibility of self-defence. Suppose an agent wishing to engage in self-defence so as to protect her own life cannot do so without killing her assailant. According to Aquinas, killing the assailant may be permissible if the intention is self defence and if the act of killing is in proportion to the end. Killing the assailant is impermissible, for example, if more violence is used than required to defend oneself.[9] Later versions of double effect also stress that the bad effect should not be the means to achieving the good effect. In his analysis, Murphy focuses on the intention, the means, and the proportionality criteria of double effect. Note that most influential versions of double effect have an additional criterion: that the action to be justified is good or at least indifferent in and of itself,[10] but Murphy is silent on this fourth 
criterion. Since this is a reply to Murphy and I can make my point without reference to this additional criterion, I will be silent on it too.

\section{Intention}

According to most formulations of double effect, for an action to be permissible, only the good effect should be intended. The bad effect should be merely a foreseen but unintended side-effect of the action to be justified. Is this the case with embryo deaths in natural reproduction? Murphy rightly argues that the intention of natural reproduction is to have a child - and not to expose embryos to risk. He writes that "One can wish for children without - as a condition of expressing that hope - also hoping that some embryos face disorders and death. The former does not entail the latter logically or morally". A commonly applied test to account for the distinction between intended and merely foreseen effects is the counterfactual test,[11] which looks at whether an agent would still perform the act if she thought that the bad effect would not occur. It is plausible that if no embryo deaths occurred in natural reproduction, prospective parents would still reproduce naturally. This suggests that Murphy is correct when he says the intention of natural reproduction is to have children, not to harm embryos.

\section{Means}

The basic idea of double effect is that a harm that might permissibly be brought about as a side effect in promoting a good end cannot be permissibly brought about as a means to that end. According to Murphy, embryo deaths in natural reproduction are not a means to having children. This, he writes, is because "embryo loss is extraneous to the conception of children that results in children since it does not have to happen and is therefore not inherently the 'bad' means by which a 'good' outcome is achieved." 
There are several ways to determine whether the bad effect of an action is a means to the good end. Murphy seems to use a criterion of closeness. According to this criterion, if the action is inevitably connected to the bad effect, we may conclude that the latter is used as a means to the good effect.[12] If we apply this criterion, it is indeed plausible that embryo deaths in natural reproduction are not a means to having a child. It is possible that a child is created via natural reproduction without any embryos dying along the way.

To strengthen his point, Murphy adds another reason for why he thinks the embryos' death is not a means to having a child: the embryos do not die in order to ensure that other embryos will make it. It is not that "some conception does not succeed because other conceptions fail", he writes. Julian Savulescu, in arguing against John Harris, has made a similar argument. Savulescu writes that "In the case of natural reproduction, these embryos are not created for the purposes of giving other embryos a greater chance of life - every embryo gets the best and equal chance of being a baby."[13] Savulescu has made this point to show, against Harris, that it is not accurate to say that the embryo is instrumentalised (used as a mere means) in natural reproduction. This is plausible.

\section{Proportionality}

In order for an action to be justifiable by double effect, the bad effect must be unintended and not a means to the good effect, but there must also be a proportionately grave reason for permitting it. Alan Donagan explains the proportionality condition as follows:[11]

Whether or not the good effect is a proportionately serious reason is determined according to the principle that evil is to be avoided or prevented wherever possible, except at the cost of an equal or worse evil. If the nonoccurrence of the good effect would be as great an evil, or a worse evil, than the occurrence of the bad effect, then it is a proportionately serious reason for it. 
Murphy argues that, "If anything can be counted as proportionate to the loss of human life, it would seem to be the new generation of new human life". It is indeed plausible that the bad side-effect of unintended embryo deaths is less bad than a situation in which no new children are brought into the world. To illustrate this, we can simply compare these deaths with the death of some of the children we bring into the world. Even though we know that typically some of our children may die prematurely, we accept this risk in order to have children. We generally think that the good of bringing children into the world outweighs the badness of some of them dying prematurely. However, as I will show in the second part of the paper, applying the proportionality condition is not as straightforward as Murphy seems to think. It may be, for example, that for it to apply to natural reproduction, we should at the same time do what we can to reduce the number of embryo deaths. Perhaps, as Murphy himself has pointed out in earlier work, and as Ord has argued more elaborately, this implies that we should prioritize the prevention of spontaneous abortions. $[4,14]$ However, since the main aim of my paper is to show that double effect cannot justify embryo deaths in standard IVF practices, I am going to remain silent on Murphy's claim that it could justify natural reproduction as I think my argument more obviously applies to double effect and embryo deaths in IVF.

\section{ASSISTED REPRODUCTION}

After arguing that one can consistently believe that the embryo is a person and accept natural reproduction, Murphy proceeds to argue that one can also consistently believe that the embryo is a person and accept assisted reproduction via IVF, which, like natural reproduction, involves the death of a large number of embryos. According to Murphy, embryo deaths in IVF are, from a moral point of view, like embryo deaths in natural reproduction and can thus also be justified by double effect. 
First, according to Murphy, only the good effect is intended in IVF. He writes that "In fertility medicine, the motive for IVF can be the same as for conception in vivo: to have a child". Second, Murphy states that the embryos' death in IVF is not the means to achieving the good end as, just like in natural reproduction, "The loss of the embryo is not the means by which other embryos thrive." Finally, Murphy argues that the proportionality condition is met too. This is because in IVF "the unwanted loss of some embryonic life seems counterbalanced by the desirable generation of new lives".

Murphy's line of thought is very similar to that of some members of the former US Council on Bioethics who also stressed the analogy between embryo deaths in IVF and natural reproduction:[15]

Even though [in IVF] more eggs are fertilized than will be transferred to a woman, each embryo is brought into being as an end in itself, not simply as a means to other ends. Precisely because one cannot tell which IVF embryo is going to reach the blastocyst stage, implant itself in the uterine wall, and develop into a child, the embryo "wastage" in IVF is more analogous to the embryo wastage in natural sexual intercourse practice by a couple trying to get pregnant than it is to the creation and use of embryos that requires (without exception) their destruction.

I think that it is indeed plausible that the intention of people who undergo IVF is to have a child and that the embryo deaths are not a means to having a child. However, even if we grant all that, a problem remains. It lies in Murphy's application of the proportionality criterion of double effect. Murphy writes that in IVF "the unwanted loss of some embryonic life seems counterbalanced by the desirable generation of new lives". This analysis may be correct if applied to certain IVF practices that do indeed resemble natural reproduction (at least, if the proportionality condition is met in natural reproduction). However, it clearly fails when applied to IVF as it is practiced in most 
countries. If we apply it to standard IVF practices, then Murphy is comparing the wrong things. I will illustrate this with a hypothetical case in a different context.

\section{Consider}

Road Building. the city council decides to build a road. To achieve this end, ten road workers will have to construct the road, three of whom are likely to die as a result of the hard labour (and we don't know beforehand who). The works will take a year to complete. The alternative is not building the road, in which case no one will die.

In this case, the good end is the completion of a new road in one year time, and the harm that occurs as a result is the death of three workers. To see whether the proportionality condition is met, we have to ask whether the badness of the death of three workers is proportionate to the badness of not achieving the good end - the completion of a new road. What we are comparing then is the absolute benefit (a new road) with the absolute harm (the death of three workers). (I am assuming it would be worse if the road was not built at all). Likewise we could, as Murphy does, compare doing IVF with not doing IVF at all. We are comparing the absolute benefit (creating a child via IVF) with the absolute harm (the death of a number of embryos). It seems to me, however, that we are comparing the wrong things.

In most countries where IVF is practised, on average five to ten embryos are produced per IVF cycle, one or two of which are transferred to the woman's womb to try to achieve a pregnancy. The remaining embryos are stored in nitrogen freezers. If an attempt to achieve a pregnancy fails, one or two embryos can be thawed for a new attempt. Cryopreservation of several embryos has the advantage that women do not have to undergo the hormone therapy and egg retrieval procedure, which entail some risk and discomfort (see below), after each failed attempt to generate a pregnancy. At the start of the IVF treatment, the couple must indicate one of the following options for 
handling of any leftover frozen embryos: (1) donation to other infertile couples, (2) donation to scientific research (most embryo research, including most embryonic stem cell research, is performed on embryos donated for research), or (3) allowing the embryos to perish. The two last options both involve the embryo's destruction, and thus no opportunity for it to develop into a child.

I will call this type of IVF woman-friendly IVF. But IVF can also be done without the creation of extra embryos likely to be consigned to death. Some countries allow IVF but prohibit the creation of extra embryos for cryopreservation purposes. For example, Italy limits the number of oocytes that can be fertilized to three and all embryos created in vitro have to be transferred to the woman's uterus. I will refer to IVF as it is done in Italy - without the creation of extra embryos - as embryo-friendly IVF.

So now that it is clear that there is not either woman-friendly IVF or no IVF, but that there is also embryo-friendly IVF, let us return to the proportionality principle of double effect.

\section{Consider a variant of Road Building:}

Road Building*: the city council decides to build a road. There are two options. The first option is as in Road Building. It involves building the road with ten workers, three of whom are likely to die. The works will take a year to complete. The second option is to build the road with ultramodern machines and only three road workers, none of whom will die. The works will take one year and four months to complete. All other things are equal.

If this alternative - building the road less quickly but without any deaths - is available, then it seems we should think of the good ends and side-effects in a relative way. Now we should construe the good effect as building the road four months more quickly and the harmful side effect as three buman deaths instead of none. It seems clear that the city council should choose the second option. The cost of 
losing three human lives is, all other thing being equal, just too high to justify the benefit of finishing the road work four months earlier. The relative benefit is too small to justify the relative harm.

If we take the same approach for woman-friendly IVF, we need to compare it with embryo-friendly IVF instead of with not doing IVF at all. The good effect of doing woman-friendly IVF will then not be the creation of a child (a child will be created either way), but the reduced health risks and

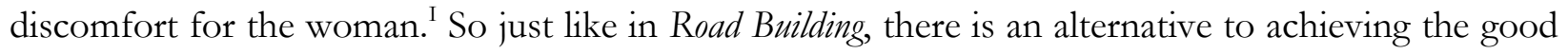
end that is less convenient. The crucial question, then, is whether the relative benefit of reducing harm to the woman due to potentially more hormone treatments and further egg retrievals is large enough to outweigh the badness of the embryo deaths. ${ }^{\text {II }}$

The hormone treatment and egg retrieval procedure involve some risks and inconveniences that are mostly mild but in some cases can be severe or even lethal. One of the more serious possible effects of the hormone treatment is the development of the ovarian hyperstimulation syndrome (OHSS), which may involve abdominal swelling and pain, nausea, vomiting and sometimes diarrhoea, and which may vary in severity. Although the risks and inconveniences should not be underestimated,

\footnotetext{
I My opponent may point out that there is another potential benefit of woman-friendly IVF: it may be more costeffective than embryo-friendly IVF. To be successful, embryo-friendly IVF may have to be repeated more frequently than woman-friendly IVF. Thus, woman-friendly IVF may have an additional advantage: more women will be able to afford it, and will thus have access to it. This may not only be more just, it is also likely to result in the generation of more 'new life'. It could then be argued that these advantages, together with the advantages to the women undergoing IVF, outweigh the badness of embryo deaths in woman-friendly IVF. However, first, this argument could only work in countries where IVF is not reimbursed. In Belgium, for example, all IVF cycles are reimbursed. Secondly, one would think that instead of allowing embryos to die, one should make IVF more accessible. That this extra advantage of woman-friendly IVF does not put enough weight in the scale to outweigh the costs of embryo deaths could also be shown by Frozen Babies. It seems that, intuitively, Sonya's way of reproducing would still be problematic, even if it would mean more women have access to fertility treatments and more babies would be born as a result. Thanks to an anonymous reviewer for pointing this potential objection out to me.

II If we apply this analysis to natural reproduction, the question is whether there is an alternative to current (embryounfriendly) natural reproduction (apart from not reproducing at all).One could argue that such an alternative is possible, if only we invested more time and effort in it. For example, if we did more research into causes and prevention of spontaneous abortion, we could make natural reproduction more embryo-friendly. The difference with embryo-friendly IVF is that, at the moment, there is no embryo friendly natural reproduction. It would be interesting to investigate whether my argument also applies to natural reproduction. However, I do not have space to do this in this paper.
} 
surely, one would not normally impose life-threatening risks to persons to reduce this sort of risk and inconvenience.

Consider another hypothetical case:

Frozen Babies. Sonya and Steve want a child. Making use of IVF they produce eight viable embryos, one of which is randomly chosen for transfer to Sonya's uterus. The remaining seven embryos, instead of being cryopreserved, are carried to term by surrogate mothers. After birth, the seven babies are (painlessly) frozen. The reason is that should something bad happen to Sonya's baby at birth or shortly afterwards, one of the frozen babies can be thawed and given to her. Sonya would thereby be spared from having to undergo the IVF procedure and the pregnancy again. Fortunately nothing goes wrong. Sonya and Steve do not want more than one baby. The frozen babies are donated to scientific research that involves a process that will kill them. This destination for any leftover babies was decided upon by Sonya and Steve at the start of the IVF treatment.

Choosing woman-friendly IVF over embryo-friendly IVF is akin to choosing to reproduce in the way pursued by Sonya and Steve. Though the primary intention of Sonya and Steve is to have a child, it seems intuitively clear that creating the frozen babies cannot be justified by double effect. The reason is that the proportionality condition is not met. Imposing such big risks on the babies is out of proportion to the good effect - preventing or reducing harm to Sonya due to the IVF procedure, the pregnancy and the delivery. If double effect cannot justify the special IVF procedure Sonya and Steve are using, then, by analogy, double effect cannot justify womanfriendly IVF either (remember that we are assuming embryos are persons). If the proportionality condition is not met in Frozen Babies, then surely it is not met in woman-friendly IVF. After all, 
the risks imposed on the embryos are to prevent a smaller harm (risks from IVF) in womanfriendly IVF than in Frozen Babies (risks from IVF, pregnancy and the delivery).

\section{EMBRYO RESEARCH}

Finally, Murphy criticizes my view that if one accepts woman-friendly IVF, then one is also committed to accepting research on embryos created especially for the purpose of research.[16] He agrees with Dan Brock, who objects to my argument because

Defenders of the doctrine of double effect might argue that [in IVF] all [embryos] are created for the purpose of reproduction, but with a possible foreseen consequence that not all will be needed for that purpose; the creation of excess embryos that might be used in research is foreseen as a possible consequence, but is not intended. On the other hand, in using IVF with no reproductive intent and solely to create embryos for use in research, their destruction is intended and not merely foreseen.[5]

However, as I just argued, intention is not the only thing that matters - proportionality matters too. Since the proportionality condition is not met in the case of woman-friendly IVF, it cannot be justified by double effect (at least not by the version of double effect endorsed by Murphy). Thus double-effect cannot be invoked to show that there is a moral difference between accepting embryo deaths in woman-friendly IVF and in embryo research, including embryo research with embryos created especially for research. My argument is not defeated by Murphy's arguments. If one does think double effect can justify woman-friendly IVF, the moral status one accords to the embryo must be low. The crucial question then remains: if the moral status of the embryo is so low that double effect can justify woman-friendly IVF, how can it provide a decisive reason against sacrificing embryos for research that can potentially save and improve the quality of life of a very large number of people? 


\section{CONCLUSION}

I have argued that Murphy's claim that embryo deaths in IVF can be justified by double effect is incorrect because the proportionality condition is not met in (standard) woman-friendly IVF practices. Murphy's argument fails to support the view (1) that IVF is permissible if the embryo is a person, and (2) that there is a moral difference between embryo deaths in IVF and in embryo research. Thus, his argument does not defeat the position that if one accepts standard IVF practices one should also accept embryo research, including research with embryos created solely for that purpose.

\section{REFERENCES:}

1. French FE, Bierman JE. Probabilities of fetal mortality. Public Health Rep 1962;10:835-37.

2. Hertig AT. The overall problem in man. In: Benirschke K, ed. Comparative Aspects of Reproductive Failure. New York, NY: Springer-Verlag 1967:11-41.

3. Leridon H. Human fertility: The Basic Components. Chicago, IL: University of Chicago Press 1977.

4. Ord T. The scourge: moral implications of natural embryo loss. Am J Bioeth 2008;7:12-9.

5. Brock DW. Is a consensus possible on stem cell research? Moral and political obstacles. J Med Ethics 2006;32:3642.

6. Sparrow R. Saviour embryos? Preimplantation genetic diagnosis as a therapeutic technology. Reprod Biomed Online 2009;20:667-74.

7. Harris J. Enhancing Evolution: The Ethical Case for Making Better People. Princeton: Princeton University Press 2007. 
8. Murphy TM. Double-effect reasoning and the conception of human embryos. J Med Ethics 2012 Published Online First 18 August 2012. doi:10.1136/medethics-2012-100534.

9. Aquinas T. (13th c). Summa Theologica II-II, Q. 64, art. 7, Of Killing. In Baumgarth WP and Regan RJ, eds. On Law, Morality, and Politics. Indianapolis/Cambridge: Hackett Publishing Co 1988:226-7.

10. Mangan J. An historical analysis of the principle of double effect. Theological Studies 1949;10:41-61.

11. Donagan A. The Theory of Morality. Chicago: the University of Chicago Press 1977:161.

12. Marquis DB. 1991. Four versions of double effect. J Med Philos 16: 515-44.

13. Savulescu J. Embryo research: are there any lessons from natural reproduction? Camb Q Healthc Ethics 2009;01:68-75(73).

14. Murphy TF. The moral significance of spontaneous abortion. J Medical Ethics 1985;11:79-83.

15. President's Council on Bioethics (2002) Human Cloning and Human Dignity: An Ethical Inquiry. The President's Council on Bioethics, Washington D.C.: Chapter 6, section 4.

16. (DELETED FOR BLIND REVIEW) 